\title{
Association Of Premature Exfoliation Of Primary Molar With Malocclusion - A Retrospective Analysis
}

\author{
Research Article
}

\author{
Lakshya Rani. S ${ }^{1}$, Aravind Kumar ${ }^{2}$, G. Maragathavalli ${ }^{3}$ \\ ${ }^{1}$ Undergraduate, Saveetha Dental College and Hospitals, Saveetha Institute of Medical and Technical Sciences(SIMATS), Saveetha University, Chen- \\ nai 600 077, Tamil Nadu, India. \\ ${ }^{2}$ Professor, Department of Orthodontics, Saveetha Dental College and Hospitals, Saveetha Institute of Medical And Technical Sciences (SIMATS), \\ Saveetha University, Chennai 600 077, Tamil Nadu, India. \\ ${ }^{3}$ Professor, Department of Oral Medicine and Radiology, Saveetha Dental college and Hospital,Saveetha Institute of Medical and Technical Sciences \\ (SIMATS), Saveetha University, Chennai, India.
}

\section{Abstract}

\begin{abstract}
This study aimed at evaluating the prevalence and association of premature exfoliation of primary molars with malocclusion. This study is a retrospective study conducted in a University hospital setting. The data regarding the age, gender and primary molars were retrieved from patients records and analysed. The data with patients records between June 2019 to March 2020 were taken and after fulfillment of inclusion and exclusion criteria, a final sample of 35 children were considered. The study population consists of 35 children with missing primary molars, who had reported to the dental OP. The data were tabulated and analysed by SPSS software and statistics done using Chi Square test with significance kept at $\mathrm{p}<0.05$. Majority of individuals with premature loss of primary second molars are found to present with malocclusion $(42.42 \%)$. In the present study, boys dominated the study population when compared to girls. The incidence of premature loss of primary second molar $(75.7 \%)$ was found to be high when compared to primary first molar. Premature exfoliation of primary second molar was found to be common in the age group 3-6 years $(42.42 \%)$. Boys were seen to have a higher prevalence of premature exfoliation of primary second molar $(48.48 \%)$ compared to girls. The study also emphasizes the importance of early detection of premature loss of primary molars to prevent future malocclusion.
\end{abstract}

Keywords: Malocclusion; Premature Loss; Exfoliation; Molars.

\section{Introduction}

Early or premature loss is defined by the loss of a deciduous tooth before the time of its natural exfoliation [1]. Traumatic dental injuries to the deciduous teeth will essentially lead to avulsion, premature exfoliation, or extraction due to any complications or poor prognosis [2]. This will ultimately affect the esthetics in case of anterior tooth loss, speech, mastication, eruption, or development of the successor permanent teeth, oral habits, and also the arch integrity [3]. Root resorption of primary teeth is affected by the environmental, hereditary, nutritional, and endocrine factors whereas the root formation of permanent dentition remained undisturbed. Furthermore, the local factors such as decay, pulp necrosis, and pulpotomy increased the rate of root resorption and hastened the exfoliation of the deciduous dentition [4]. Although the periodontally compromised teeth and trauma lead to early loss, the main cause is dental caries [5]. Early loss of primary teeth leads to earlier or delayed eruption of the successor teeth. Paediatric patients may experience different effects such as dental rotation, extrusion of the antagonist tooth, dental crowding, development of deleterious habits, impaction of the successor teeth and dental arch reduction [6]. The relationship between the prevalence of premature tooth loss, ethnicity and importance of environmental factors has been demonstrated by several studies [7].

In a study performed in Brazil a total of 369 children (6 - 10 years old) were examined to evaluate the prevalence of early loss of primary molar in school children [8]. In that study it was found

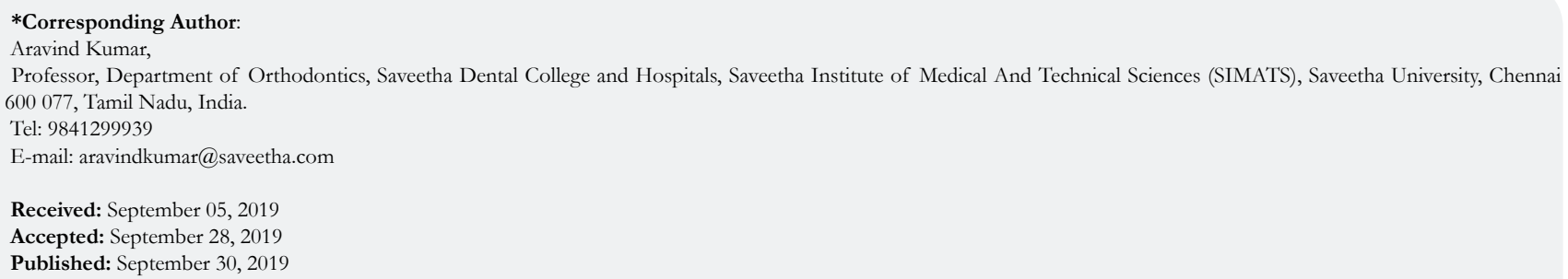

Copyright: Aravind Kumar 2019 . This is an open-access article distributed under the terms of the Creative Commons Attribution License, which permits unrestricted use, distribution and reproduction in any medium, provided the original author and source are credited. 
that $24.9 \%$ of the sample experienced loss of one or more primary molars. The prevalence was highest among the 9 year olds $(70.2 \%)$ and the most commonly missing teeth with the lower primary molars $(74.3 \%)[9,10]$. In Saudi Arabia, a sample of 344 children aged 4 - 9 years was examined. It was found that the mean DMFT value was 6.6. The (d) component was very high (5.35), while the value of $(\mathrm{m})$ was $0.64(9.7 \%)$ [11].

Growth and development and drifting patterns of teeth are closely interdependent. The primary dentition plays a very important role in the child's growth and development, not only in terms of speech, chewing, appearance, and prevention of deleterious oral habits but also in the guidance and eruption of permanent teeth [12]. It is generally accepted that the premature loss of deciduous teeth is associated with the malocclusion of permanent dentition. Management of space problems associated with the transitional stages from primary to permanent dentition is a routine component of pedodontic practice [13]. It is generally accepted that the premature loss of primary teeth, especially a molar, may lead to lack of space, malocclusion, midline discrepancies in the permanent dentition. In addition, the premature loss of primary teeth reduces the arch length required for the succeeding tooth and therefore predisposes the crowding, rotation and impaction of the permanent teeth [14]. However, the present study was designed to determine the incidence and association of premature exfoliation of E's and malocclusion.

\section{Materials and Methods}

\section{Study setting and sampling}

This study is a single- centred retrospective study, carried out in a private dental college. The present study was approved by Institutional ethical committee [IEC] (Ethical approval number: SDC/ SIHEC/2020/DIASDATA/0619-0320) and was in accordance with the ethical standards that were stipulated. All available records of patients from June 2019 - April 2020 were examined and a total of 86000 case sheets were reviewed. Patients below 10 years and those with early loss of primary molars were included in the study. Those who visited outside the time frame, and older than 10 years were excluded from the study. Cross verification of data for error was done by presence of additional reviewers and by photographs evaluation. Two examiners were involved in the study. Any patient with incomplete data was excluded from the study.

\section{Data collection}

Acquisition of data was done from the hospital database which records all patient details. The study included 35 children with early loss of primary molars. The collected data were grouped based on the patients with early loss of primary first and primary second molar. Age was categorised into 3 - 6 years, 7- 10 years. Gender was categorised into males and females. Malocclusion like spacing, crowding, overbite, overjet and deep bite were assessed by the photographs from the patients records. The data were entered in the system in a methodical manner. For this study, data regarding age, gender and prematurely exfoliated primary molars and malocclusion were collected. The data was then entered in excel manually and imported to SPSS for analysis. Incomplete or censored data were excluded from the study.

\section{Statistical analysis}

The statistical analysis was done using SPSS software (SPSS version 21.0, SPSS, Chicago II, USA). Descriptive statistics was used to summarise the demographic information of the patients included in this study. Descriptive statistics is used for the acquisition of frequency distribution of the data. Chi-square test was applied to analyse the association of different variables. Statistical significance was kept at $\mathrm{p}<0.05$.

\section{Results and Discussion}

The study population consists of 35 children in the age group between 3 - 10 years. Based on the distribution of study population by age, $45.4 \%$ of the children were found within the age group of $3-6$ years and $54.55 \%$ of the children were found within the age group of 7 - 10 years (Figure 1). Based on the distribution of population by gender, $66.6 \%$ of the children were found to be males and $33.3 \%$ of the children were found to be females (Figure 2). Based on the incidence of prematurely exfoliated primary molars, $75.7 \%$ of the children were found to present with premature exfoliation of primary second molar and $24.2 \%$ of the children were found to present with premature exfoliation of primary first molar (Figure 3). Based on the prevalence of malocclusion among the study population, $60.6 \%$ of the children were found to present with malocclusion and $39.3 \%$ of the population were not

Figure 1. Bar chart represents the distribution of the study population by age. The $\mathrm{X}$ axis denotes the age group of the children and the $\mathrm{Y}$ axis denotes the number of children with early loss of primary molars. From the graph, it is observed that the majority of the patients with early loss of primary molars were found within the age group of $7-10$ years (54.5\%) when compared to the other age group.

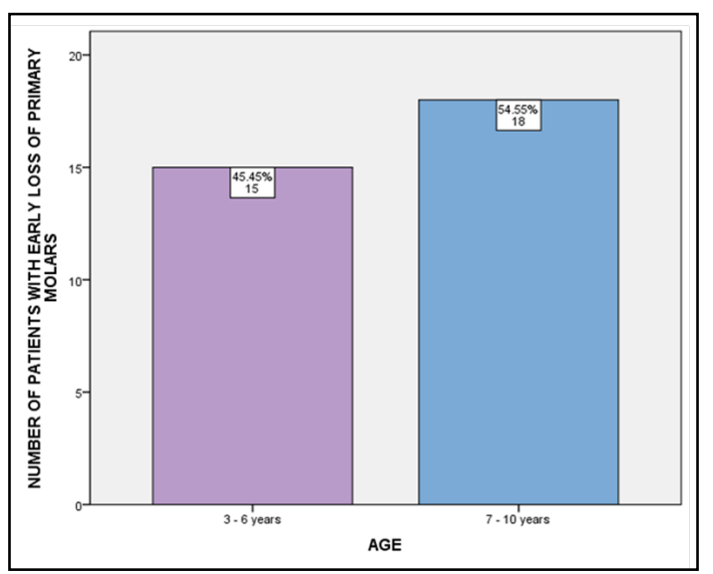


Figure 2. Bar chart represents the distribution of study population by gender. The $X$ axis denotes the gender of the children with early loss of primary molars and the $\mathrm{Y}$ axis denotes the number of children with early loss of primary molars. From the graph it is observed that the majority of the patients with early loss of primary molars were found to be males $(66.6 \%)$ when compared to females( $33.3 \%)$.

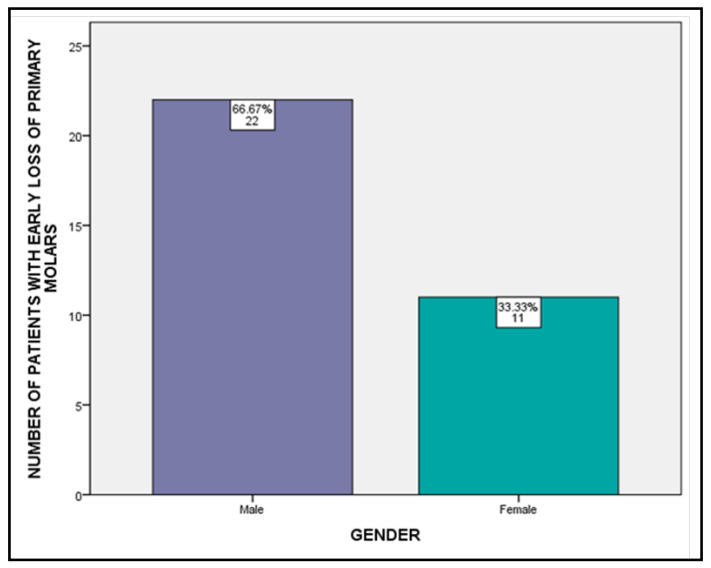

Figure 3. Bar chart represents incidence of prematurely exfoliated primary molars among study population. The $\mathrm{X}$ axis denotes prematurely exfoliated primary molars and the $\mathrm{Y}$ axis denotes the number of patients with early loss of primary molars. From the graph it is observed that the incidence of premature exfoliation of primary second molar $(75.7 \%)$ is more prevalent among the study population.

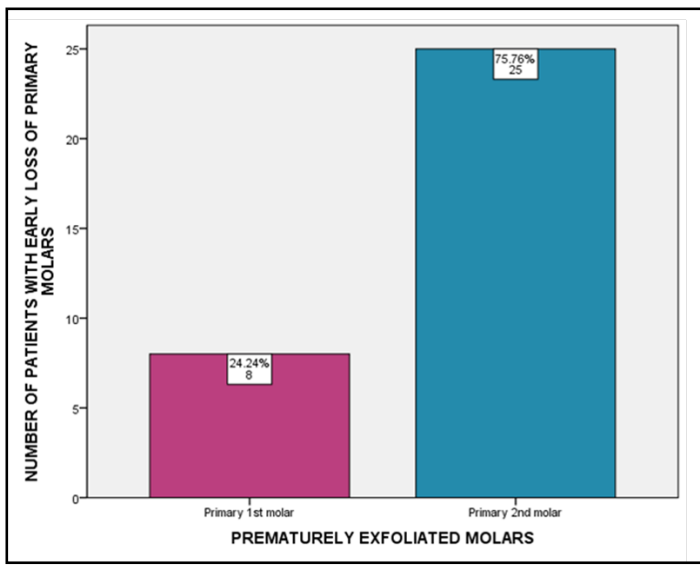

Figure 4. Bar chart represents incidence of malocclusion among the study population. The $\mathrm{X}$ axis denotes malocclusion and the $\mathrm{Y}$ axis denotes the number of patients with early loss of primary molars. From the graph it is observed that the majority of the patients with early loss of primary molars had malocclusion $(60.6 \%)$.

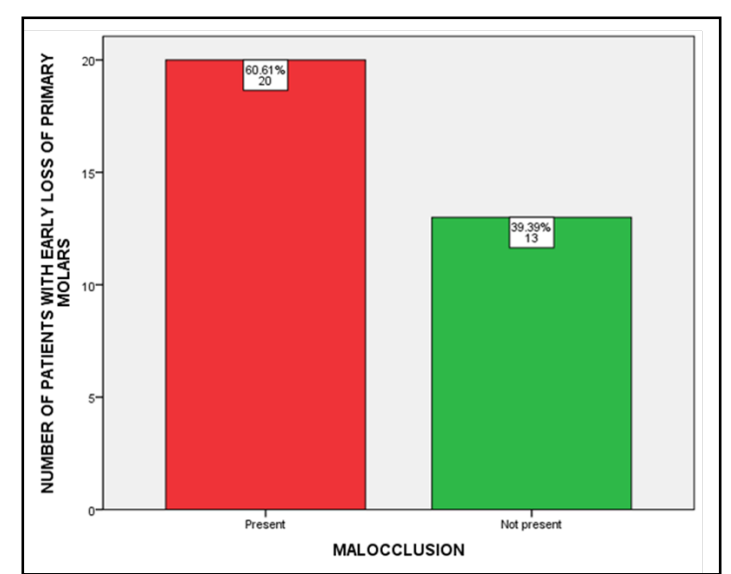

found to present with malocclusion (Figure 4).

Based on the association between age groups and premature exfoliation of primary molars, $42.4 \%$ of the children with premature exfoliation of primary second molar and $3 \%$ of the children with premature exfoliation of primary first molar were found within the age group of 3 - 6 years; $33.3 \%$ of the children with premature exfoliation of primary second molar and $21.2 \%$ of the children with premature exfoliation of primary first molar were found within the age group of 7-10 years (Figure 5). Based on the association between gender and premature exfoliation of primary molars, $48.4 \%$ of the children with premature exfoliation primary second molar and $18.1 \%$ of the children with premature exfoliation of primary first molar were found to be males; $27.2 \%$ of the children with premature exfoliation of primary second molar and $6 \%$ of the children with premature exfoliation of primary first molar were found to be females (Figure 6).

Based on the association between age groups and malocclusion, $27.2 \%$ of the children with malocclusion and $18.1 \%$ of the chil- 
dren without malocclusion were found within the age group of 3-6 years; $33.3 \%$ of the children with malocclusion and $21.2 \%$ of the children without malocclusion were found within the age group of 7-10 years (Figure 7). Based on the association between gender and malocclusion, $42.4 \%$ of the children with malocclusion and $24.2 \%$ of the children without malocclusion were found to be males; $18.1 \%$ of the children with malocclusion and $15.1 \%$ of the children without malocclusion were found to be females (Figure 8). The association between premature exfoliation of primary molars and malocclusion were assessed and was found that, in children with prematurely exfoliated primary second molar, $42.2 \%$ had malocclusion and $18.1 \%$ had no malocclusion; In children with prematurely exfoliated primary first molar only $33.3 \%$ had malocclusion and 6\% had no malocclusion (Figure 9).

Premature loss of a primary tooth is of concern not only because of the loss of function but also because of the increased possibility that other teeth may drift [11]. Prediction of subsequent premature loss of primary teeth would be useful in determining treatment [11, 14]. Moreover, the premature loss of deciduous teeth influences the development of normal occlusion and creates an increased need for orthodontic treatment [14].

The early loss of primary teeth has been observed in research studies throughout many areas around the world [14, 4]. In this study we examined 35 children in the age group of 3-10 years
These children were selected with the inclusion criteria of premature loss of primary molars. In our study $75.7 \%$ of the children had premature loss of primary second molar. This result is similar to the findings of a study performed in Saudi Arabia [11] which found that $51 \%$ of the children had premature loss of primary second molar. A study reported that $47.3 \%$ of children in Denmark [1] and $65.4 \%$ of children in a study performed in Brazil [15] were found to have premature tooth loss. Compared to the Danish and Brazilian results, the children in the current study experienced higher incidence of premature loss of primary second molar. A study reported that the prevalence of early loss was higher in the first molars when compared with the second molars in children with the age group of 5 - 10 years [4] and this was similar to the findings of Najlaa Alamoudi [9] which is found to be contrary to our results It has been previously stated that the premature loss of primary teeth can affect the normal eruption time of permanent successors by either retarding or accelerating their emergence [16].

Literature reviews have shown a relationship between the premature loss of deciduous teeth and the prevalence of malocclusion [17]. In our current study $60.6 \%$ of the children had malocclusion with premature loss of primary molars and $42.2 \%$ of the children had malocclusion with premature loss of primary second molar. This is supported by the findings of Proffit et al., [18]. However, premature loss of primary teeth is considered to be the

Figure 5. Bar chart represents the association between the age and prematurely exfoliated primary molars The $\mathrm{X}$ axis denotes the age group of the patients and the $\mathrm{Y}$ axis denotes the number of patients with early loss of primary molars. From the graph, it is observed that the majority of the patients with premature exfoliation of primary second molar were found within the age group of $3-6$ years $(42.4 \%)$. Chi square $p$ value $-0.434(P>0.05)$ which showed no significant association between age groups and prematurely exfoliated primary molars among the study population.

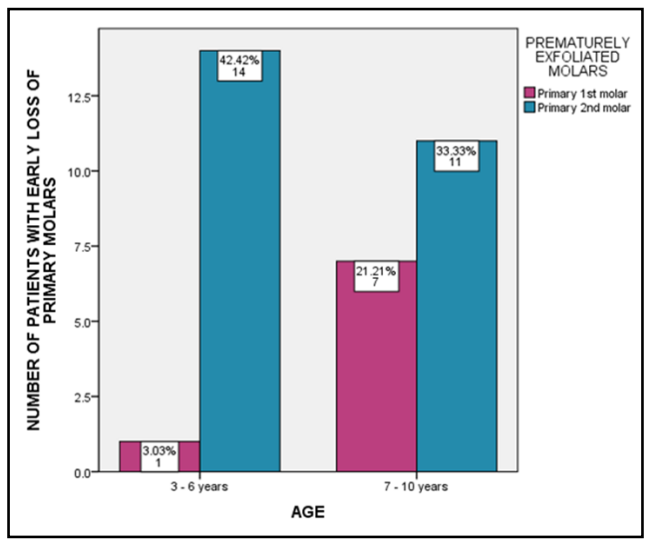

Figure 6. Bar chart represents the association between the gender and prematurely exfoliated primary molars . The $\mathrm{X}$ axis denotes the gender of the patients and the $\mathrm{Y}$ axis denotes the number of patients with early loss of primary molars. From the graph, it is observed that the majority of the patients with premature exfoliation of primary second molar were found to be males (48.4\%). Chi square $\mathrm{p}$ value - $0.454(P>0.05)$ which showed no significant association between gender and prematurely exfoliated primary molars among the study population.

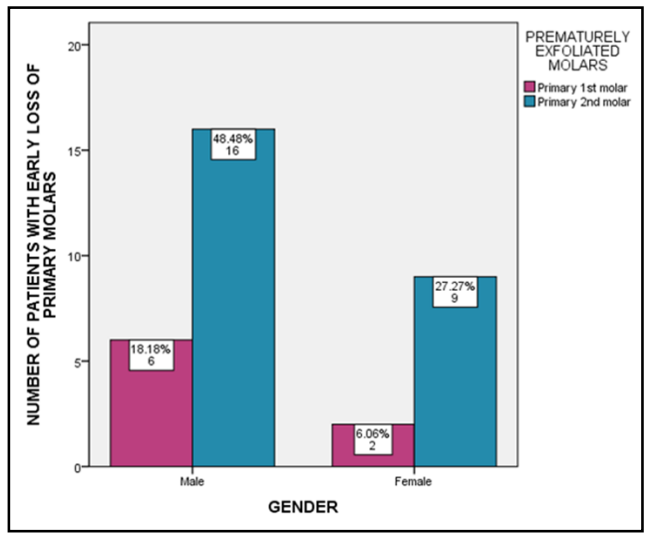


Figure 7. Bar chart represents the association between the age and malocclusion. The $\mathbf{X}$ axis denotes the age group of the patients and the $\mathrm{Y}$ axis denotes the number of patients with early loss of primary molars. From the graph, it is observed that the majority of the patients with malocclusion were found within the age group of $7-10$ years $(33.3 \%)$. Chi square $p$ value $-0.614(P>0.05)$ which showed no significant association between age groups and malocclusion among the study population.

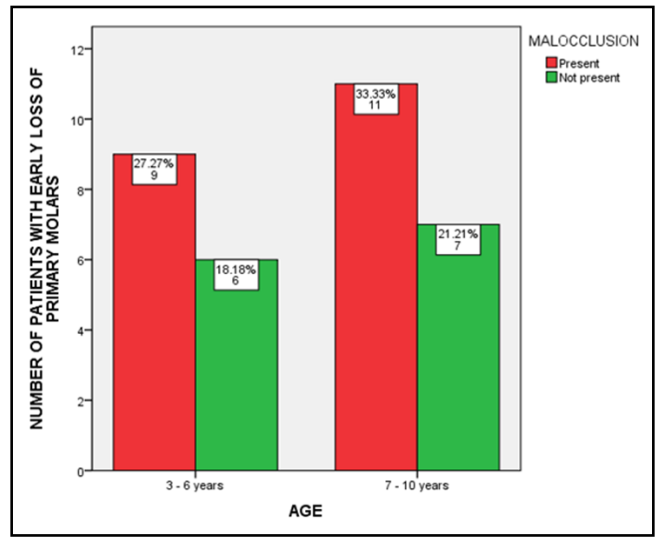

Figure 8. Bar chart represents the association between gender and malocclusion. The $X$ axis denotes the gender of the patients and the $\mathrm{Y}$ axis denotes the number of patients with early loss of primary molars. From the graph, it is observed that the majority of the patients with malocclusion were found to be males $(42.4 \%)$. Chi square $p$ value- $0.446(P>0.05)$ which showed no significant association between gender and malocclusion among the study population. Hence it is statistically not significant.

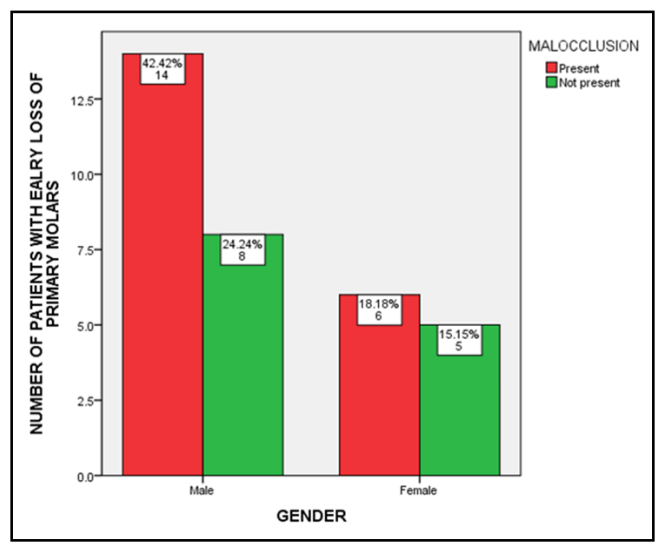

Figure 9. Bar chart represents the association between malocclusion and prematurely exfoliated primary molars.The $\mathrm{X}$ axis denotes the malocclusion and the $\mathrm{Y}$ axis denotes the number of patients with early loss of primary molars. From the graph, it is observed that the majority of the patients with malocclusion were found to have premature exfoliation of primary second molar (42.4\%). Chi square $\mathrm{p}$ value-0.299 ( $P>0.05)$ which showed no significant association between malocclusion and prematurely exfoliated primary molars among the study population.

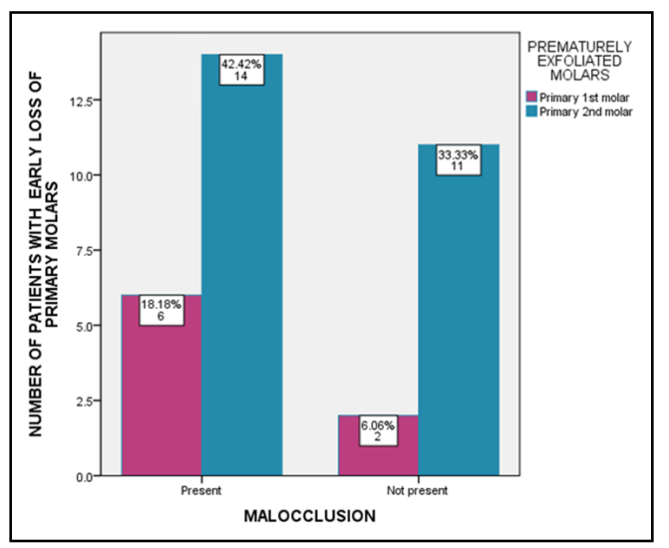

most common local factor leading to malocclusion because of its interference with the harmony of the adult dentition, resulting in crowding caused by the migration of adjacent teeth [19].

Finally,because of the deleterious effects of early loss of primary teeth, it is necessary to increase oral awareness by conducting School dental health programs to inform the children and parents about the deleterious effects caused by the early loss of primary teeth. Children with early loss of primary teeth should be instructed to have space maintainers if necessary. And also the parents of those children should be advised to bring their children to dental hospital for dental procedures regularly [18]. Previously our team has conducted numerous studies which include in vitro studies [20], review [21], case report [22], survey, microscopic studies [23] and clinical trials $[22,24,34]$. The limitations of the study could be a smaller sample size which could have impacted the signifi- 
cance of the study results. Further studies with large populations are needed to associate our findings with other regions for better results and significance.

\section{Conclusion}

Within the limits of our study, it was observed that the prevalence of premature loss of primary second molar $(75.7 \%)$ was found to be high when compared to primary first molar. Majority of individuals with premature loss of primary second molars are found to present with malocclusion $(42.42 \%)$. Premature exfoliation of primary second molar was found to be common in the age group 3-6 years $(42.42 \%)$. Boys were seen to have a higher prevalence of premature exfoliation of primary second molar $(48.48 \%)$ compared to girls. This finding emphasizes the importance of increasing awareness about this issue and to focus further efforts towards early to loss prevention and intervention to maintain healthy dentition. In addition, our findings also emphasize the importance of early detection of premature loss of primary teeth to prevent malocclusion.

\section{Acknowledgement}

This research was supported by Saveetha dental college and hospital. We would like to acknowledge the Information Technology department of the institution for their support in data collection.

\section{References}

[1]. Pedersen J, Stensgaard K, Melsen B. Prevalence of malocclusion in relation to premature loss of primary teeth. Community Dent Oral Epidemiol. 1978 Jul;6(4):204-9.Pubmed PMID: 278705.

[2]. Holan G, Needleman HL. Premature loss of primary anterior teeth due to trauma--potential short- and long-term sequelae. Dent Traumatol. 2014 Apr;30(2):100-6.Pubmed PMID: 24138100.

[3]. Haralabakis NB, Yiagtzis SC, Toutountzakis NM. Premature or delayed exfoliation of deciduous teeth and root resorption and formation. Angle Orthod. 1994 Apr;64(2):151-7.

[4]. Ahamed SS, Reddy VN, Krishnakumar R, Mohan MG, Sugumaran DK, Rao AP. Prevalence of early loss of primary teeth in 5-10-year-old school children in Chidambaram town. Contemp Clin Dent. 2012 Jan;3(1):27-30. Pubmed PMID: 22557893.

[5]. Murshid SA, Al-Labani MA, Aldhorae KA, Rodis OM. Prevalence of prematurely lost primary teeth in 5-10-year-old children in Thamar city, Yemen: A cross-sectional study. J Int Soc Prev Community Dent. 2016 Aug;6(Suppl 2):S126-30.Pubmed PMID: 27652244.

[6]. Cavalcanti AL, Alencar CR, Bezerra P, Granville-Garcia AF. Prevalence of early loss of primary molars in school children in campina grande, Brazil. Pak Oral Dent J. 2008;28(1):113-6

[7]. Cardoso L, Zembruski C, Femandes DS, Boff I, Pessin V. Evaluation of prevalence of malocclusion in relation to premature loss of primary teeth. Pesq Bras Odontoped Clin Integr. 2005;5:17-22.

[8]. de Almeida Heilborn JC, Küchler EC, da Silva Fidalgo TK, Antunes LA, Costa MC. Early primary tooth loss: prevalence, consequence and treatment.Int. J. Dent. 2011 Jun 24;10(3):126-30.

[9]. Alamoudi N. The prevalence of crowding, attrition, midline discrepancies and premature tooth loss in the primary dentition of children in Jeddah, Saudi Arabia. J Clin Pediatr Dent. 1999 Fall;24(1):53-8.Pubmed PMID: 10709544.

[10]. Owusu GB, Al-Amri MY, Stewart BL, Sabbah W. Status of dental caries among 4-9 year-old children attending dental clinic in a military hospital in Tabuk, KSA. Saudi Dent J. 2005;17(3):126-31.

[11]. al Ghanim NA, Adenubi JO, Wyne AA, Khan NB. Caries prediction model in pre-school children in Riyadh, Saudi Arabia. Int J Paediatr Dent. 1998 Jun;8(2):115-22.Pubmed PMID: 9728096.

[12]. Setia V, Pandit IK, Srivastava N, Gugnani N, Sekhon HK. Space maintainers in dentistry: past to present. J Clin Diagn Res. 2013 Oct;7(10):2402-5. Pubmed PMID: 24298544

[13]. Gilbride MJ, Smith WP. Eruption of teeth in the nose following trauma to the primary and permanent dentitions. Br Dent J. 2005 Feb 26;198(4):199200.Pubmed PMID: 15731794.

[14]. Jayachandar D, Gurunathan D, Jeevanandan G. Prevalence of early loss of primary molars among children aged 5-10 years in Chennai: A cross-sectional study. J Indian Soc Pedod Prev Dent. 2019 Apr-Jun;37(2):115-119. Pubmed PMID: 31249172.

[15]. Monte-Santo AS, Viana SVC, Moreira KMS, Imparato JCP, Mendes FM, Bonini GAVC. Prevalence of early loss of primary molar and its impact in schoolchildren's quality of life. Int J Paediatr Dent. 2018 Nov;28(6):595601.Pubmed PMID: 30105883.

[16]. Al-Shahrani N, Al-Amri A, Hegazi F, Al-Rowis K, Al-Madani A, Hassan KS. The prevalence of premature loss of primary teeth and its impact on malocclusion in the Eastern Province of Saudi Arabia. Acta Odontol Scand. 2015;73(7):544-9.Pubmed PMID: 25804261.

[17]. Sleichter GG. The influence of premature loss of deciduous molars and the eruption of their successors. Angle Orthod. 1963 Oct;33(4):279-83.

[18]. Proffit WR, Fields HW Jr, Moray LJ. Prevalence of malocclusion and orthodontic treatment need in the United States: estimates from the NHANES III survey. Int J Adult Orthodon Orthognath Surg. 1998;13(2):97-106.Pubmed PMID: 9743642.

[19]. Tausche E, Luck O, Harzer W. Prevalence of malocclusion in the early mixed dentition and orthodontic treatment need. Am J Orthod Dentofacial Orthop. 2005 Mar 1;127(3):394.

[20]. Kamisetty SK, Verma JK, Arun, Sundari S, Chandrasekhar S, Kumar A. SBS vs Inhouse Recycling Methods-An Invitro Evaluation. J Clin Diagn Res. 2015 Sep;9(9):ZC04-8.Pubmed PMID: 26501002.

[21]. Viswanath A, Ramamurthy J, Dinesh SP, Srinivas A. Obstructive sleep apnea: awakening the hidden truth. Niger J Clin Pract. 2015 Jan-Feb;18(1):1-7. Pubmed PMID: 25511335.

[22]. Felicita AS. Orthodontic management of a dilacerated central incisor and partially impacted canine with unilateral extraction - A case report. Saudi Dent J. 2017 Oct;29(4):185-193.Pubmed PMID: 29033530.

[23]. Ramesh Kumar KR, Shanta Sundari KK, Venkatesan A, Chandrasekar S. Depth of resin penetration into enamel with 3 types of enamel conditioning methods: a confocal microscopic study. Am J Orthod Dentofacial Orthop. 2011 Oct;140(4):479-85.Pubmed PMID: 21967934.

[24]. Sivamurthy G, Sundari S. Stress distribution patterns at mini-implant site during retraction and intrusion--a three-dimensional finite element study. Prog Orthod. 2016;17:4.Pubmed PMID: 26780464.

[25]. Samantha C, Sundari S, Chandrasekhar S, Sivamurty G, Dinesh S. Comparative Evaluation of Two Bis-GMA Based Orthodontic Bonding Adhesives - A Randomized Clinical Trial. J Clin Diagn Res. 2017 Apr;11(4):ZC40ZC44.Pubmed PMID: 28571259.

[26]. Krishnan S, Pandian S, Kumar S A. Effect of bisphosphonates on orthodontic tooth movement-an update. J Clin Diagn Res. 2015 Apr;9(4):ZE01-5. Pubmed PMID: 26023659.

[27]. Vikram NR, Prabhakar R, Kumar SA, Karthikeyan MK, Saravanan R. Ball Headed Mini Implant. J Clin Diagn Res . 2017 Jan;11(1):ZL02-ZL03.

[28]. Felicita AS. Quantification of intrusive/retraction force and moment generated during en-masse retraction of maxillary anterior teeth using mini-implants: A conceptual approach. Dental Press J Orthod. 2017 SepOct;22(5):47-55.Pubmed PMID: 29160344.

[29]. Rubika J, Felicita AS, Sivambiga V. Gonial angle as an indicator for the prediction of growth pattern. World J Dent. 2015;6(3):161-3.

[30]. Jain RK, Kumar SP, Manjula WS. Comparison of intrusion effects on maxillary incisors among mini implant anchorage, $\mathrm{j}$-hook headgear and utility arch. J Clin Diagn Res. 2014 Jul;8(7):ZC21-4.Pubmed PMID: 25177631.

[31]. Pandian KS, Krishnan S, Kumar SA. Angular photogrammetric analysis of the soft-tissue facial profile of Indian adults. Indian J Dent Res. 2018 MarApr;29(2):137-143.Pubmed PMID: 29652003.

[32]. Felicita AS, Chandrasekar S, Shanthasundari KK. Determination of craniofacial relation among the subethnic Indian population: a modified approach - (Sagittal relation). Indian J Dent Res. 2012 May-Jun;23(3):305-12. Pubmed PMID: 23059564.

[33]. Dinesh SP, Arun AV, Sundari KK, Samantha C, Ambika K. An indigenously designed apparatus for measuring orthodontic force. J Clin Diagn Res. 2013 Nov;7(11):2623-6.Pubmed PMID: 24392423.

[34]. Felicita AS. Orthodontic extrusion of Ellis Class VIII fracture of maxillary lateral incisor - The sling shot method. Saudi Dent J. 2018 Jul;30(3):265269.Pubmed PMID: 29942113. 